\title{
FLUKTUASI PENYALURAN KREDIT DI PT BANK MANDIRI TBK
}

\author{
Cindy Ananda Putri \\ Sugeng Hariadi \\ Mintarti Ariani \\ Fakultas Bisnis dan Ekonomika, Universitas Surabaya \\ Raya Kalirungkut, Surabaya, Indonesia 60293
}

\begin{abstract}
ABSTRAK
PT Bank Mandiri tbk merupakan salah satu Bank BUMN di Indonesia. Sebagai lembaga perbankan yang bertugas dalam menghimpun serta menyalurkan dana kepada masyarakat dalam bentuk kredit, Bank Mandiri perlu menerapkan prinsip kehati-hatian dalam memberikan kredit kepada para debiturnya untuk menghindari adanya kredit macet yang akan berdampak pada kondisi kesehatan bank. Penelitian ini bertujuan untuk menganalisis pengaruh Gross Domestic Product (GDP), Inflasi, Dana Pihak Ketiga (DPK) dan Non Performing Loan (NPL) terhadap jumlah kredit yang diberikan oleh PT Bank Mandiri Tbk. Data penelitian ini bersumber dari Badan Pusat Statistik dan dari 13 laporan tahunan bank Mandiri periode 2008-2020. Metode perhitungan pada penelitian ini menggunakan metode ECM, metode OLS dan uji regresi linear berganda. Hasil penelitian menunjukkan bahwa Gross Domestic Product (GDP) dan Dana Pihak Ketiga (DPK) berpengaruh positif dan signifikan terhadap jumlah kredit PT Bank Mandiri Tbk yang berarti bahwa semakin besar tingkat GDP maka jumlah kredit Bank Mandiri akan semakin meningkat. Non Performing Loan (NPL) berpengaruh positif dan tidak signifikan terhadap jumlah kredit Bank Mandiri. Sedangkan Inflasi berpengaruh negatif dan tidak signifikan terhadap jumlah kredit Bank Mandiri.
\end{abstract}

Kata Kunci: dana pihak ketiga, gross domestic product, inflasi, kredit, non performing loan

\begin{abstract}
PT Bank Mandiri tbk is one of the state-owned banks in Indonesia. As a banking institution in charge of collecting and distributing funds to the public in the form of credit, Bank Mandiri needs to apply the principle of prudence in providing credit to its debtors to avoid bad loans which will have an impact on the health condition of the bank. This study aims to analyze the effect of Gross Domestic Product (GDP), Inflation, Third Party Funds (DPK) and Non Performing Loans (NPL) on the amount of credit granted by PT Bank Mandiri Tbk. The data for this research is sourced from the Central Statistics Agency and from 13 annual reports of Bank Mandiri for the period 2008-2020. The calculation method in this study uses the ECM method, the OLS method and multiple linear regression tests. The results show that Gross Domestic Product (GDP) and Third Party Funds (DPK) have a positive and significant effect on the amount of credit of PT Bank Mandiri Tbk, which means that the greater the level of GDP, the number of Bank Mandiri loans will increase. Non-Performing Loans (NPL) have a positive and insignificant effect on the amount of Bank Mandiri's credit. Meanwhile, inflation has a negative and insignificant effect on the amount of Bank Mandiri's credit

Keywords: credit, gross domestic product, inflation, non performning loan, third party funds
\end{abstract}

DOI: https://doi.org/10.24123/jeb.v25i2.4836

\section{PENDAHULUAN}

Bank merupakan perusahaan yang bergerak dalam bidang keuangan, yang berarti aktivitas perbankan selalu berkaitan dalam bidang keuangan (Kasmir, 2014). Bank berperan sebagai mitra masyarakat karena Lembaga ini bertugas menghimpun dan menyalurkan dana kepada masyarakat dalam bentuk kredit. Masyarakat yang membutuhkan modal untuk menjalankan usaha, baik usaha mikro, usaha menengah dan usaha makro, dapat melakukan pengajuan kredit di bank untuk dapat menjalankan usaha.

GDP menunjukkan peningkatan pendapatan masyarakat maupun perusahaan. Kemampuan untuk membayar hutang akan meningkat jika pendapatan masyarakat maupun perusahaan mengalami peningkatan. Darmawan dkk (2017) menyatakan bahwa semakin besar tingkat GDP maka kredit perbankan akan semakin meningkat. GDP dapat meningkat apabila terdapat kebijakan pemerintah yang dapat mendorong pertumbuhan kredit (Susi, 2017).

Bank Indonesia (2021) menyatakan bahwa Inflasi adalah kenaikan harga barang dan jasa secara umum dan terus menerus dalam jangka waktu tertentu. Inflasi dan GDP merupakan salah satu faktor eksternal mengenai kredit yang diberikan oleh bank. Perhitungan Inflasi dilakukan oleh Badan Pusat Statistik (BPS), link ke metadata SEKI-IHK. Menurut Indri (2017), untuk dapat mengendalikan laju 
Inflasi, Bank Indonesia dapat melakukan suatu kebijakan dengan menaikkan tingkat suku bunga pada periode tertentu.

Objek penelitian ini dipilih karena PT Bank Mandiri Tbk sempat mengalami kasus kredit bermasalah pada periode 2016-2017 sehingga berdampak pada jumlah kredit perbankan. Neria dkk (2020) menyatakan bahwa meski NPL suatu bank tinggi, perusahaan dapat menyalurkan kredit dalam jumlah besar. Hal ini karena kredit merupakan salah satu sarana perusahaan untuk mendapatkan keuntungan. Faktor internal yang dapat mempengaruhi jumlah kredit bank selain NPL adalah Dana Pihak Ketiga (DPK). Apsari \& Bella (2015) menyatakan bahwa tingginya kemampuan bank dalam menghimpun dana pihak ketiga (DPK) akan berakibat kepada tingginya jumlah kredit yang diberikan bank kepada masyarakat.

Tujuan dilakukan penelitian ini adalah menganalisis pengaruh Gross Domestic Product (GDP), Inflasi, serta Dana Pihak Ketiga (DPK) terhadap jumlah kredit yang diberikan oleh PT Bank Mandiri Tbk. Penelitian ini diharapkan dapat bermanfaat bagi pembaca, bagi manajemen perbankan dan bagi pemerintah untuk memberikan wawasan serta pengetahuan dalam hal penyaluran kredit perbankan.

\section{METODOLOGI PENELITIAN}

Penelitian ini dilakukan di PT Bank Mandiri Tbk secara kuantitatif. Objek yang digunakan dalam penelitian adalah publikasi laporan keuangan triwulan PT Bank Mandiri Tbk yang diunduh dari website Otoritas Jasa Keuangan (OJK) di halaman resmi OJK serta laporan tahunan triwulan yang dipergunakan untuk mencari data triwulan Gross Domestic Product (GDP) dan Inflasi di Indonesia.

Penelitian ini menggunakan data sekunder yang diperoleh dari laporan publikasi PT Bank Mandiri Tbk selama periode 2008-2020 yang dapat diakses pada halaman resmi Otoritas Jasa Keuangan (OJK), serta laporan GDP dan Inflasi selama periode 2008-2020 yang dapat diakses pada halaman resmi Badan Pusat Statistik (BPS).

Data time series yang diperoleh selanjutnya diolah menggunakan teknik Error Correction Model (ECM), Ordinary Least Square (OLS) dan Uji Regresi berganda menggunakan EVIEWS-9 dan SPSS. Ketiga uji tersebut digunakan untuk mengetahui pengaruh variabel independen yaitu GDP, Inflasi, DPK dan NPL terhadap variabel dependen yaitu kredit yang diberikan PT Bank Mandiri Tbk.

\section{HASIL DAN DISKUSI}

Berdasarkan 52 observasi, nilai rata-rata jumlah kredit yang diberikan oleh PT Bank Mandiri kepada para debiturnya (dalam jutaan) adalah sebesar Rp441.000.000,00, nilai tengah adalah sebesar Rp4.300.000,00 nilai maksimal dan minimal masing-masing sebesar Rp792.000.000,00 dan Rp123.000.000,00 serta nilai standar deviasi sebesar Rp214.000.000,008. GDP mempunyai nilai ratarata $106.5 \%$, nilai tengah sebesar $5.16 \%$, nilai maksimal dan minimal masing-masing sebesar $52,85 \%$ dan $-5.32 \%$ serta nilai standar deviasi sebesar 7,32\%. Inflasi mempunyai nilai rata-rata $5,0 \%$ dengan nilai tengah sebesar $4,31 \%$, nilai maksimal dan nilai minimal masing-masing sebesar $12,14 \%$ serta nilai standar deviasi sebesar 2,47\%. Nilai rata-rata DPK (dalam jutaan) adalah sebesar Rp518.000.000,00, nilai tengah sebesar 517.000.000,00, nilai maksimal sebesar Rp909.000.000,00 dan nilai minimal sebesar Rp211.000.000,00 serta nilai standar deviasi sebesar Rp197.000.000,00. Nilai rata-rata NPL sebesar $0,96 \%$, nilai tengah sebesar $0,66 \%$, nilai maksimal dan nilai minimal masing-masing sebesar $5,90 \%$ dan $0,32 \%$ serta nilai standar deviasi sebesar $1,04 \%$.

\section{Uji Mackinnon, White and Davidson (MWD)}

Tabel 1 Hasil uji MWD

\begin{tabular}{clllll}
\hline Variabel & $\begin{array}{c}\text { Unstandardized } \\
\text { B }\end{array}$ & $\begin{array}{c}\text { Coefficients } \\
\text { Std. Error }\end{array}$ & $\begin{array}{c}\text { Standardized } \\
\text { Coefficients } \\
\text { Beta }\end{array}$ & $t$ & Sig. \\
\hline Z1 & -165578080 & 306062991,5 & $-0,028$ & $-0,541$ & 0,591 \\
Z2 & 0,022 & 0,762 & 0,001 & 0,029 & 0,977 \\
\hline
\end{tabular}

Sumber: Data primer diolah, 2021

Tabel 1 menunjukkan bahwa menggunakan derajat kepercayaan 95\% $(\alpha=5 \%)$ ditemukan bahwa kedua variabel Z1 dan Z2 tidak signifikan karena nilai signifikannya >0,05. Karena nilai Z1 dan Z2 
tidak signifikan maka fungsi model empiris yang akan digunakan adalah model regresi linear yang ditunjukkan dengan persamaan sebagai berikut :

1. Uji Stasioneritas

$$
\ln \text { Kredit }=\mathrm{a} 0+\mathrm{at} \operatorname{lnGDP}+\mathrm{a} 2 \ln I n f l a s i+\mathrm{a} 3 \ln \mathrm{DPK}+\mathrm{a} 4 \ln N P L+\mathrm{e}
$$

Tabel 2 Hasil uji stasioneritas

\begin{tabular}{lccc}
\hline Variabel & Intercept & Trend and Intercept & None \\
\hline Kredit & + & + & + \\
GDP & $* * *$ & $* * *$ & + \\
Inflasi & + & + & + \\
DPK & + & $* * *$ & + \\
NPL & $* * *$ & $* * *$ & $* * *$ \\
\hline
\end{tabular}

Sumber: Data primer diolah, 2021

Keterangan :

$$
\begin{array}{ll}
+ & =\text { Data } \text { non } \text { stasioner } \\
* & =\text { Data stasioner pada taraf signifikansi } 10 \% \\
* * & =\text { Data stasioner pada taraf signifikansi } 5 \% \\
* * * & =\text { Data stasioner pada taraf signifikansi } 1 \%
\end{array}
$$

Berdasarkan lima variabel yang telah dilakukan uji stasioneritas dengan menggunakan bentuk Intercept, trend and intercept dan none masih banyak yang datanya bersifat non-stasioner (Tabel 2).

2. Uji Derajat Integrasi

Melalui uji derajat integrasi, ADF digunakan dalam diferensiasi kedua untuk menstasionerkan semua variabel sehingga akan diperoleh hasil sebagai berikut:

\begin{tabular}{|c|c|}
\hline & $=$ Data non stasioner \\
\hline & $=$ Data stasioner pada taraf signifikansi $10 \%$ \\
\hline ** & $=$ Data stasioner pada taraf signifikansi $5 \%$ \\
\hline$* * *$ & $=$ Data stasioner pada taraf signifikansi $1 \%$ \\
\hline
\end{tabular}

Tabel 3 Hasil uji derajat integrasi

\begin{tabular}{lccc}
\hline Variabel & Intercept & Trend and Intercept & None \\
\hline Kredit & $* * *$ & $* * *$ & $* * *$ \\
GDP & $* * *$ & $* * *$ & $* * *$ \\
Inflasi & $* * *$ & $* * *$ & $* * *$ \\
DPK & $* * *$ & $* * *$ & $* * *$ \\
NPL & $* * *$ & $* * *$ & $* * *$ \\
\hline
\end{tabular}

Sumber: Data primer diolah, 2021

Keterangan :

Berdasarkan tabel 3 diketahui bahwa semua variabel yang digunakan pada penelitian sudah

\begin{tabular}{|c|c|c|c|c|}
\hline Trace Statistic & \multicolumn{4}{|c|}{ Tabel 4 Uji kointegrasi } \\
\hline $\begin{array}{l}\text { Hypothesized } \\
\text { No. of CE(s) }\end{array}$ & Eigenvalue & $\begin{array}{c}\text { Trace } \\
\text { Statistic }\end{array}$ & $\begin{array}{l}0,05 \text { Critical } \\
\text { Value }\end{array}$ & Prob. \\
\hline None* & 0.890819 & 193.2155 & 69.81889 & 0.0000 \\
\hline \multicolumn{5}{|c|}{ Max-Eigen Statistic } \\
\hline $\begin{array}{l}\text { Hypothesized } \\
\text { No. of } C E(s)\end{array}$ & Eigenvalue & $\begin{array}{c}\text { Trace } \\
\text { Statistic }\end{array}$ & $\begin{array}{l}0,05 \text { Critical } \\
\text { Value }\end{array}$ & Prob. \\
\hline None* & 0.890819 & 110.7376 & 33.87687 & 0.0000 \\
\hline
\end{tabular}
bersifat stasioner pada diferensiasi kedua. Alasan dilakukannya uji derajat integrasi pada diferensiasi kedua dikarenakan masih terdapat variabel yang tidak stasioner pada diferensiasi pertama.

3. Uji Kointegrasi

Sumber: Data primer diolah, 2021

Berdasarkan hasil uji kointegrasi ditemukan bahwa terdapat hubungan kointegrasi antar variabel dependen dan independennya yang berarti hubungan jangka panjang diterima dan 
menolak Ha (Tabel 4). Nilai probability pada uji kointegrasi sebesar 0.0000 yang menunjukkan signifikansi adanya kointegrasi antar variabel.

4. Estimasi Model ECM Engle-Granger

Sebelum melakukan estimasi model ECM perlu dilakukan analisis regresi untuk mengetahui pengaruh jangka panjang antar variabel dependen dan variabel independen, sehingga ditemukan model regresi linear sebagai berikut :

KREDITt $=-1.42 \mathrm{E}+08+8793150 \mathrm{GDP}-4231190 \mathrm{INFLASI}+1.073622 \mathrm{DPK}+5443662 \mathrm{NPL}+\varepsilon \mathrm{t}$

Berdasarkan hasil dari analisis model regresi linear ditemukan bahwa probabilitas GDP sebesar 0,0414, variabel Inflasi sebesar 0,2856, variabel DPK sebesar 0,00 dan variabel NPL sebesar 0,4962. Sedangkan nilai Adjusted R-Squared dari hasil model regresi linear termasuk pada nilai yang tinggi yaitu sebesar 0.943246. Sebagaimana diketahui bahwa data pada penelitian ini bersifat non stasioner pada tingkat level, maka diperlukan koreksi kesalahan agar dapat menyesuaikan ketidakseimbangan yang terjadi dengan model ECM.

Setelah mengetahui pengaruh jangka panjang antar variabel, perlu dilakukan analisisregresi model ECM, sehingga ditemukan model regresi sebagai berikut :

$\mathrm{D}($ KREDITt $)=13841706+3604968 \mathrm{D}(\mathrm{GDPt})+334368.8 \mathrm{D}($ INFLASI $)-0.047299 \mathrm{D}(\mathrm{DPK} \mathrm{t})$

$+3123691 \mathrm{D}(\mathrm{NPL})+0.021049 \mathrm{ECT}(-1)+\varepsilon t$

Berdasarkan hasil analisis ECM, ditemukan bahwa Nilai koefisien ECT sebesar 0.021049dapat diartikan bahwa terdapat $2 \%$ ketidakseimbangan pada pengaruh jangka pendek yang terkoreksi setiap satu periodenya.

5. Uji Asumsi OLS

Uji asumsi OLS yang dilakukan pada penelitian ini meliputi uji normalitas, uji linearitas, uji multikolinearitas, uji autokorelasi dan uji heteroskedastisitas dengan menggunakan bantuan program Eviews-9. Pengujian normalitas dengan metode Jarque-Bera test ditemukan nilai probabilitas sebesar $0.222551>0.05$ yang berarti bahwa data berdistribusi normal. Pengujian linearitas dengan metode Ramsey Reset test ditemukan nilai $F$ statistic sebesar 0,2625>0.05 yang berarti bahwa model yang digunakan memenuhi asumsi linearitas.

Pengujian multikolinearitas dengan metode Variance Inflation Factors ditemukan Nilai VIF berkisar 0,006- 2,169 dimana nilai tersebut $<10$ yang berarti bahwa model terbebas dari multikolinearitas. Pada uji autokorelasi dengan metode Langrange Multiplier ditemukan nilai Prob Chi-Square sebesar 0,9472 > 0.05 yang berarti bahwa model terbebas dari autokorelasi. Serta pengujian heteroskedastisitas dengan metode harvey ditemukan nilai probabilitas F 0,5966 $>0.05$ yang berarti bahwa tidak terjadi heteroskedastisitas dalam model.

6. Uji regresi linear berganda

Tabel 5 Hasil analisis regresi linear berganda

\begin{tabular}{llll}
\hline \multicolumn{1}{c}{ Model } & \multicolumn{2}{c}{ Unstandardized Coefficients } & Sig. \\
\cline { 2 - 3 } & B & \multicolumn{1}{c}{ Std. Error } & \\
\hline (Constant) & -141594050 & 47834792,75 & 0,005 \\
GDP (X1) & 8793150,403 & 4193302,475 & 0,041 \\
Inflasi (X2) & $-4231190,394$ & 3916961,626 & 0,286 \\
DPK (X3) & 1.074 & 0,050 & 0,000 \\
NPL (X4) & 5443661,518 & 7938095,559 & 0,496 \\
\hline
\end{tabular}

Sumber: Data primer diolah, 2021

Persamaan regresi dari Tabel 5 adalah:

$$
\mathrm{Y}=-141.594 .050+8.793 .150,403 \mathrm{X} 1-4.231 .190,394 \mathrm{X} 2+1.074 \mathrm{X} 3+5.443 .661,518 \mathrm{X} 4+\mathrm{e}
$$

Berdasarkan Tabel 5, nilai b1 sebesar 8.793.150,403 dengan signifikansi sebesar 0,041 dengan nilai signifikan tersebut lebih kecil dari tingkat kesalahan 0,05 yang berarti bahwa GDP berpengaruh positif dan signifikan terhadap jumlah kredit PT Bank Mandiri Tbk. Nilai b2 sebesar -4.231.190,394 dengan signifikansi sebesar 0,286 yang berarti bahwa Inflasi berpengaruh negatif 
dan tidak signifikan terhadap jumlah kredit PT Bank Mandiri Tbk. Nilai b3 sebesar 1.074 dengan signifikan sebesar 0,000 artinya bahwa DPK mempunyai pengaruh positif dan signifikan terhadap jumlah kredit PT Bank Mandiri Tbk. Nilai b4 sebesar 5.443.661,518 dengan nilai signifikan sebesar 0,496 artinya NPL mempunyai pengaruh positif dan tidak signifikan terhadap jumlah kredit PT Bank Mandiri Tbk.

Dalam uji F ditemukan bahwa nilai F hitung sebesar 212.905 dengan nilai signifikan sebesar 0,000 yang berarti bahwa secara simultan variabel GDP, Inflasi, DPK dan NPL berpengaruh signifikan terhadap jumlah kredit pada PT Bank Mandiri tbk. Pada uji $R^{2}$ diperoleh nilai Adjusted $R$ Square sebesar 0,943 yang artinya pengaruh dari variabel independen terhadap variabel dependen sebesar 94,3\%. Dapat disimpulkan bahwa variabel GDP, Inflasi, DPK dan NPL mampu menjelaskan variabel kredit sebesar 94,3\%.

\section{Pengaruh GDP terhadap jumlah kredit Bank Mandiri}

Berdasarkan hasil analisis yang telah dibahas sebelumnya, ditemukan bahwa nilai b1 sebesar 8.793.150,403 dengan signifikansi sebesar 0,041. Dengan menggunakan tingkat kesalahan sebesar 0,05 dimana nilai signifikan yang diperoleh nilainya lebih kecil dari tingkat kesalahan. Dapat disimpulkan bahwa Gross Domestic Product (GDP) berpengaruh positif dan signifikan terhadap jumlah kredit PT Bank Mandiri Tbk. Sehingga dapat diartikan bahwa semakin besar tingkat GDP maka jumlah kredit yang disalurkan oleh Bank akan semakin meningkat.

Wahyuni dkk (2017) pada penelitiannya menyatakan bahwa GDP berpengaruh positif dan signifikan terhadap penyaluran kredit perbankan, hal tersebut ditunjukkan pada nilai koefisien regresi sebesar 0,449 dengan nilai signifikan sebesar 0,021 yang lebih kecil daritingkat kesalahan sebesar 0,05 . Aditya (2018) Pada penelitiannya juga menyatakan bahwa produk domestik bruto atau GDP berpengaruh positif dan signifikan terhadap penyalurankredit Bank umum di Indonesia, hal tersebut ditunjukkan pada nilai koefisien yang diperoleh yaitu sebesar 6961.02252642 dengan signifikan sebesar 0,0000 yang lebih kecil dari tingkat kesalahan 0,05 .

GDP menunjukkan ukuran pendapatan dan pengeluaran suatu perekonomian yang berarti bahwa jika GDP pada suatu sektor mengalami peningkatan maka pergerakan usaha di suatu sektor tersebut akan terlihat. Apabila suatu sektor bergerak untuk mengembangkan usahanya maka permintaan kredit pada sektor tersebut akan meningkat. Sehingga diperoleh kesimpulan bahwa jika GDP mengalami peningkatan maka jumlah kredit yang disalurkan oleh Bank juga akan meningkat.

\section{Pengaruh Inflasi terhadap jumlah kredit Bank Mandiri}

Berdasarkan hasil analisis diperoleh nilai b2 sebesar -4.231.190,394 dengan signifikansisebesar 0,286 yang lebih besar dari tingkat kesalahan 0,05 . Sehingga dapat diartikan bahwa Inflasi mempunyai pengaruh negatif dan tidak signifikan terhadap jumlah kredit PT Bank Mandiri Tbk. Hasil penelitian ini didukung dari penelitian terdahulu yang juga meneliti mengenai kredit Bank Mandiri. Vania, dkk (2021) menunjukkan bahwa inflasi mempunyai pengaruh negatif dan tidak signifikan terhadap penyaluran kredit Bank Mandiri. Hasil penelitian yang dikemukakan oleh penelitian terdahulu menunjukkan hasil yang sama terhadap hasil penelitian ini.

Indri (2017) juga menyatakan bahwa variabel inflasi pada penelitiannya tidakberpengaruh dan tidak signifikan terhadap penyaluran kredit perbankan, hal tersebut dibuktikan pada hasil analisa t hitung $0,653<\mathrm{t}$ tabel 2,037 dengan signifikansi 0,518 dimana nilai signifikan tersebut lebih besar dari 0,05. Maria dkk (2021) pada penelitiannya juga mengemukakan bahwa inflasi dinyatakan berpengaruh negatif dan tidak signifikan terhadap penyaluran kredit, hal tersebut juga dapat dibuktikan pada hasil uji t penelitian tersebut yang menyatakan bahwa nilai probabilitas yang diperoleh sebesar 0,0632 yang nilainya lebih besar dari tingkat kesalahan yaitu 0,05 .

Hal tersebut dapat dijelaskan bahwa naiknya tingkat inflasi di Indonesia menyebabkan masyarakat akan menarik dana yang disimpan dalam bank sehingga jumlah kredit yang diberikan oleh bank kepada para debiturnya akan mengalami penurunan. Kredit merupakan salah satu sumber pendapatan perbankan, sehingga apabila jumlah kredit yang diberikan oleh Bank menurun maka secara otomatis pendapatan perbankan juga akan mengalami penurunan. 


\section{Pengaruh DPK terhadap jumlah kredit Bank Mandiri}

Berdasarkan hasil analisis dapat dilihat bahwa nilai b3 sebesar 1.074 dengan nilaisignifikan sebesar 0,00, dimana nilai signifikan tersebut lebih kecil dari tingkat kesalahan 0,05. Sehingga dapat diartikan bahwa DPK berpengaruh positif dan signifikan terhadap jumlah kreditPT Bank Mandiri Tbk. Hal tersebut berarti apabila dana pihak ketiga (DPK) mengalami peningkatan maka jumlah kredit juga akan ikut meningkat karena dana yang diterima dari masyarakat dapat disalurkan kembali kepada masyarakat.

Hasil dari penelitian ini sejalan dengan penelitian terdahulu yang membahas mengenai kredit perbankan. Vania dkk (2021) pada penelitianya memberikan hasil yang sama pada penelitian ini, dimana hasil analisis variabel DPK sebesar 0,995 dengan signifikan 0,000 sehingga memperoleh hasil DPK berpengaruh positif dan signifikan terhadap penyaluran kreditbank. Wayan dkk (2016) juga menyatakan pada penelitiannya yang memperoleh hasil bahwa DPK berpengaruh positif dan signifikan terhadap penyaluran kredit karena nilai $p$-value $=0,000<\alpha(0,05)$.

Dana Pihak Ketiga merupakan sumber dana terbesar daripada sumber lainnya. Bank sebagai lembaga keuangan yang bertugas dalam menghimpun dana dari masyarakat dan kemudian menyalurkan kembali kepada masyarakat yang membutuhkan sangat mengandalkan Dana Pihak Ketiga. Hal tersebut dikarenakan dengan adannya DPK kegiatan operasional perbankan dapat berjalansecara baik. Apabila Bank dapat memberikan kredit kepada masyarakat yang membutuhkan dana untuk keperluan usaha maupun konsumsi, maka taraf hidup masyarakat akan meningkat karena telah terpenuhi kebutuhannya. Sehingga dapat disimpulkan bahwa semakin banyak DPK yang berhasil dihimpun oleh Bank maka semakin banyak kredit yang dapat disalurkan.

\section{Pengaruh NPL terhadap jumlah kredit Bank Mandiri}

Berdasarkan hasil analisis dibuktikan bahwa Non Performing Loan (NPL) berpengaruh positif dan tidak signifikan terhadap jumlah kredit PT Bank Mandiri Tbk. Hal tersebut dibuktikan dari hasil analisis bahwa nilai b4 sebesar 5.443.661,518 dengan signifikan sebesar 0,496 yang lebih besar dari tingkat kesalahan 0,05. Dapat diartikan bahwa semakin tinggi angka NPL maka jumlah kredit yang diberikan akan semakin tinggi, tetapi pada tingkat yang tidak signifikan. Hasil dari penelitian ini didukung berdasarkan penelitian terdahulu yang menyatakan hasil sama.

Pudji dkk (2014) pada penelitiannya menyatakan bahwa NPL tidak berpengaruh signifikan terhadap penyaluran kredit perbankan di Indonesia, hal tersebut dibuktikan dari nilaisignifikan yang diperoleh sebesar 0,8686 yang lebih besar dari tingkat kesalahan 0,05 . (Setyawan, 2016) pada penelitiannya juga menyatakan hasil yang sejalan pada penelitian ini, dimana hasil perhitungan yang diperoleh pada penelitian tersebut menunjukkan bahwa nilai t hitung 0.336 lebih kecil dari t tabel yaitu 1.660 dan tingkat signifikansi lebih besar dari 0,05 yang berarti bahwa NPL berpengaruh positif dan tidak signifikan terhadap penyaluran kredit perbankan.

Bank yang tidak menerapkan prinsip kehati-hatian dalam menyalurkan kredit kepada para debiturnya, kemungkinan besar akan menyebabkan terjadinya Non Performing Loan (NPL). Bank yang memiliki tingkat NPL tinggi dapat diartikan bahwa Bank tersebut tidak sehat, yang dapat menyebabkan ketidakmampuan Bank dalam menyalurkan Kredit. Meskipun tingkat NPL pada perbankan tinggi, Bank masih dapat memberikan kredit kepada para debiturnya dalam jumlah besar dengan menggunakan dana cadangan yang telah disimpan oleh Bank, karena pada umumnya penyaluran kredit merupakan salah satu sumber pendapatan utama perbankan.

\section{Pengaruh GDP, Inflasi, DPK dan NPL secara simultan terhadap jumlah kredit Bank Mandiri}

Berdasarkan hasil analisis GDP, Inflasi, DPK dan NPL secara bersama-sama berpengaruh signifikan terhadap jumlah kredit PT Bank Mandiri Tbk. Hal tersebut dibuktikan pada hasil analisis GDP atau nilai b1 sebesar 8.793.150,403 dengan signifikansi sebesar 0,041 yang berarti bahwa GDP berpengaruh positif dan signifikan terhadap jumlah kredit Bank Mandiri. Hasil analisis Inflasi atau b2 sebesar -4.231.190,394 dengan signifikansi sebesar 0,286 yang berarti bahwa Inflasi berpengaruh negatif dan tidak signifikan terhadap jumlah kredit Bank Mandiri. Hasil analisis DPK atau b3 sebesar 1.074 dengan nilai signifikan sebesar 0,00 yang berarti bahwa DPK berpengaruh positif dan signifikan terhadap jumlah kredit Bank Mandiri. Serta hasil analisis NPL atau b4 sebesar 5.443.661,518 dengan signifikan sebesar 0,496 yang berarti bahwa NPL berpengaruh positif dan tidak signifikan terhadap jumlah kredit Bank Mandiri. 


\section{KESIMPULAN DAN SARAN}

Berdasarkan hasil estimasi dan pembahasan yang telah diuraikan pada bab sebelumnya, maka diperoleh kesimpulan bahwa Gross Domestic Product (GDP) berpengaruh positif dan signifikan terhadap jumlah kredit PT Bank Mandiri Tbk. Sehingga dapat diartikan bahwa semakin besar tingkat GDP maka jumlah kredit yang disalurkan oleh Bank Mandiri akan semakin meningkat. Inflasi mempunyai pengaruh negatif dan tidak signifikan terhadap jumlah kredit PT Bank Mandiri Tbk. Sehingga dapat diartikan bahwa semakin tinggi tingkat Inflasi di Indonesia maka jumlah kredit yang disalurkan oleh Bank Mandiri akan semakin menurun. DPK berpengaruh positif dan signifikan terhadap jumlah kredit PT Bank Mandiri Tbk. Hal tersebut berarti apabila dana pihak ketiga (DPK) mengalami peningkatan maka jumlah kredit yang disalurkan oleh Bank Mandiri juga akan ikut meningkat karena dana yang diterima dari masyarakat dapat disalurkan kembali kepada masyarakat. Non Performing Loan (NPL) berpengaruh positif dan tidak signifikan terhadap jumlah kredit PT Bank Mandiri Tbk. Dapat diartikan bahwa semakin tinggi angka NPL maka jumlah kredit yang disalurkan oleh Bank Mandiri akan semakin tinggi, tetapi pada tingkat yang tidak signifikan. GDP, Inflasi, DPK dan NPL secara simultan berpengaruh signifikan terhadap jumlah kredit PT Bank Mandiri Tbk.

\section{DAFTAR PUSTAKA}

Aisyah, S. (2018). Pengaruh Suku Bunga Kredit, Kurs, Inflasi dan Subsidi Bahan Bakar Minyak (BBM) Terhadap Konsumsi Mobil di Indonesia Tahun 2009-2017. Yogyakarta.

Apsari, B. A. (2015). Analisis Pengaruh DPK, CAR, NPL, ROA dan Suku Bunga SBI Terhadap Penyaluran Kredit Perbankan (Studi Kasus Pada Bank Umum yang Terdaftar di Bursa Efek Indonesia Periode 2009-2013). Jurnal Ilmiah.

Astuty, P; Asri. (2014). Analisis Pengaruh Dana Pihak Ketiga, Non Performing Loan, Return on Asset dan Inflasi Terhadap Penyaluran Kredit Perbankan di Indonesia. Jurnal Ekonomi, 16.

Bank Indonesia. (2021). Diambil kembali dari www.bi.go.id.

Darmawan, G. A. S; Wahyuni, M. A; Atmadja, A. T. (2017). Pengaruh Capital Adequancy Ratio (CAR), Non Performing Loan (NPL), Produk Domestik Bruto (PDB), dan Return On Asset (ROA) Terhadap Penyaluran Kredit Perbankan (Studi Empiris Pada PerusahaanPerbankan yang Terdaftar di Bursa Efek Indonesia Periode 2013-2015. e-Journal S1 Ak Universitas Pendidikan Ganesha, 8 .

Dimas. (2020, september 30). Cara Menguji Model ECM (Error Correction Model) Data Time Series di Eviews 9. Diambil kembali dari Dimas Blogger: https://www.dimaschannel.com/2020/09/cara-menguji-model-ecm-error- correction.html

Do Carmo Gomes Pinto, N. G; Bagiada, K; Parameswara, Anak.A.G.A. (2020). Pengaruh DPK, NPL dan Inflasi Terhadap Penyaluran Kredit Pada PT Bank Mandiri periode tahun 2014-2018. Warmadewa Economic Development Journal, 3(2), 73-79.

Eklesia, M. I; Riyadi, S. (2021). Pengaruh Dana Pihak Ketiga, Inflasi, Modal Bank, dan Suku Bunga Dasar Kredit Terhadap Penyaluran Kredit. Jurnal Ilmu Manajemen, 10(2), 101- 110.

Igirisa, I. M. (2017). Pengaruh Suku Bunga, Inflasi dan Nilai Tukar Terhadap Penyaluran Kredit Pada Perbankan di Kota Samarinda. eJournal Administrasi Bisnis, 5(4), 904-916.

Kasmir. (2014). Bank dan lembaga keuangan lainnya. Jakarta: Rajawali Pers.

Mertha Jaya, I. L. (2020). Metode Penelitian Kuantitatif dan Kualitatif. Yogyakarta: Anak Hebat Indonesia.

Naro, V. M.S; Purnami, A.A. S; Wulandari, I. G. A. A;. (2021). Pengaruh Dana Pihak Ketiga, BI Rate dan Inflasi Terhadap Penyaluran Krediit Pada PT Bank Mandiri Periode 2014-2018. Warmadewa Economic Development Journal, 4(1), 28-38.

Niteriasihani, M; Cipta, W; Surendra, I. W;. (2016). Pengaruh Dana Pihak Ketiga, Capital Adequancy Ratio dan Non Performing Loan Terhadap Penyaluran Kredit Pada Bank Perkreditan Rakyat (BPR) di Kabupaten Klunngkung Tahun 2011-2013. e-Journal Bisma Universitas Pendidikan Ganesha, 4.

P Usanti, Dr. Tr; Shomad, Prof Dr. Abd;. (2016). Hukum Perbankan. Jakarta: Kencana.

Putra, A. M. (2018). Pengaruh Inflasi, PDB, DAN Suku Bunga Kredit Terhadap Penyaluran Kredit Bank Umum di Indonesia (2007-2016). Jurnal Ilmiah. 
Setyawan, O. (2016). Pengaruh DPK, CAR, NPL, ROA, SBI dan Pertumbuhan Ekonomi Terhadap Penyaluran Kredit Perbankan Pada Bank Umum Yang Teraftar di Bursa Efek Indonesia. Jurnal Akuntansi, Kewirausahaan dan Bisnis, 1, 125-139.

Sugiyono. (2016). Metode Penelitian Kuantitatif, Kualitatif, dan R\&D. Bandung: IKAPI.

Susi. (2017, Februari). Pengaruh Suku Bunga Kredit dan Produk Domestik Bruto TerhadapPenyaluran Kredit Perbankan Bank Umum Pemerintah di Indonesia. JOM Fekon, 4. 